ISSN 2518-1521 (Online), ISSN 2226-2830 (Print)

ВІСНИК МАРІУПОЛЬСЬКОГО ДЕРЖАВНОГО УНІВЕРСИТЕТУ

СЕРІЯ: ІСТОРІЯ. ПОЛІТОЛОГІЯ, 2019, ВИП. 25

УдК 321.64

\title{
Л.Н. Шумский
}

\section{КАРЛ ШМИТТ О ПОЛИТИЧЕСКИХ ТЕХНОЛОГИЯХ АМЕРИКАНСКОГО И ЕВРОПЕЙСКОГО ИМПЕРИАЛИЗМА В МЕЖДУНАРОДНОМ ПРАВЕ}

В статье проанализировань позиции немецкого политического мыслителя $u$ выдаюшегося ученого-правоведа Карла Шмитта относительно стратегических $u$ тактических действий американского и европейского империализма, направленных на расширение сфер политического и экономического господства на мировой арене в рамках международного права.

Ключевые слова: империализм, международное право, Лига начий, закон, война, мир, государство, договор.

DOI 10.34079/2226-2830-2019-9-25-143-151

Современное государство в своем развитии неизбежно вступает во взаимодействие с другими государствами в рамках определенных объединительных структур на основе международного права и признания национальных суверенитетов. Украина в этом отношении не является исключением. Государство находится в стадии политической модернизации, и этим обуславливаются объективные сложности в поиске адекватных алгоритмов политических процессов, обеспечивающих сохранение независимости в эпоху глобальных противостояний между империалистическими амбициями Запада и Востока. В связи с этим особого внимания заслуживает политическое наследие К. Шмитта, где заложены потенциальные механизмы подготовки и принятия решений для предотвращения угрозы национальному суверенитету.

Творчество К. Шмитта достаточно широко изучено зарубежными исследователями такими как Р. Меринг, Г. Машке, Х. Кварич, Х. Оттманн, Б. Рютерс, А. Филиппов, А. Михайловский, К. Лапшин и др. Среди отечественных ученых в дело популяризации идей К. Шмитта, включая тему данной статьи, внесли О. Базалук, Б. Зажигаев, А. Крысенко, В. Терлецкий, А. Фисун, Ю. Шейко и др.

В основу нашего исследования вошла работа К. Шмитта «USA und die völkerrechtlichen Formen des modernen Imperialismus» («США и международно-правовые формы современного империализма». 1932 г.) [4], которая представляется отечественной политической науке впервые.

Американский империализм отмечает К. Шмитт считается по общепринятым представлениям самым современным империализмом, потому что он, прежде всего экономический империализм, а невоенный. «Экономическое» выносится на передний план, чтобы вообще завуалировать факт империализма при помощи противопоставления экономики и политики в XIX веке, когда «экономическое» квалифицировалось как «не политическое» и соответственно «политическое» рассматривалось как «не экономическое». В этой связи К. Шмитт упоминает рассуждения известного экономиста и политолога Й. Шумпетера, утверждавшего в 1919 г., что «действия англосаксов не 
ISSN 2518-1521 (Online), ISSN 2226-2830 (Print)

ВІСНИК МАРІУПОЛЬСЬКОГО ДЕРЖАВНОГО УНІВЕРСИТЕТУ

СЕРІЯ: ІСТОРІЯ. ПОЛІТОЛОГІЯ, 2019, ВИП. 25

являются империализмом, поскольку экономическая направленность означает лишь мирную экспансию» [4, с. 349]. К. Шмитт отмечает, что лозунг «экономическое» против «политического» выдвинул еще Д. Вашингтон в своем прощальном послании в 1796 г. «максимально возможные объемы торговли с самыми разными государствами, при минимальном участии политики». Несколько позже в знаменитой доктрине Монро также предусматривались широкие возможности торговли европейских государств с Америкой, но без признаков политики. Когда наступают эти моменты «политического», решают, разумеется, США. К. Шмитт считает, что общепринятая в XIX в. позиция приоритета «экономического» в противостоянии с «политическим» утратила актуальность.

Процесс расширения властного могущества империализма, сопровождается поиском определенных «обоснований» и разработкой принципов легитимации действий, которые приобретают немирный характер. Империализму необходимы убедительные международно-правовые понятия и положения, которые представляют собой преимущественно идеологические инсценировки и преследуют, кроме того пропагандистские цели. В подобных «обоснованиях» в истории человечества никогда не было недостатка, и без них никогда не было бы международного права. В своем анализе К. Шмитт показывает, как формировались основы легитимации тактики империализма и обращает внимание на то, что международное право до середины XIX в. называлось «международным правом христианских народов». На Парижском конгрессе 1856 г. в «семью наций» была принята Турция, нехристианское государство, и это событие стало принципиально новым явлением, в значительной мере повлиявшим на практику международных отношений. Речь идет не только о «пересмотре идеологических аспектов, но и о создании возможностей заключения неправомерных договоров между независимыми государствами, что означает игнорирование положений юридических законов одного из партнеров» [4, с. 350].

Со временем, отмечает К. Шмитт, дифференциация христианских и нехристианских государств эволюционировала в более перспективную для империализма типологию: цивилизованных, нецивилизованных и полуцивилизованных народов. Это стало фундаментом для формирования международно-правовых понятий и методов в интересах европейского империализма. По отношению к полуцивилизованным народам, поясняет мыслитель, империалистическое господство осуществляется в форме протекторатов, тогда как нецивилизованные народы становятся колониями. Особенность разделения народов на цивилизованные, нецивилизованные и полуцивилизованные, четко проявилась в ст. 22 Устава Лиги наций от 1919 г., где записано, что «есть народы, которые еще не в состоянии самостоятельно управлять в сложных условиях существующих реалий; священной обязанностью цивилизации является взять эти народы под опеку и обеспечить им возможность для самостоятельного управления» [3]. К. Шмитт считает, что ст. 22 является иллюстрацией европейского империализма, самым наглядным примером легитимирующей функции разделения народов на цивилизованные и нецивилизованные народы, на основании чего цивилизованные народы наделяют себя правами в форме мандатов, протекторатов и колоний курировать менее цивилизованные народы, другими словами, господствовать над ними.

Что касается Америки, то она пошла дальше в практике формирования понятий, методов и технологий международно-правового обеспечения господства. США, безусловно, не отвергают различия между христианскими и нехристианскими народами, цивилизованными и нецивилизованными государствами, но при этом предлагается 
ISSN 2518-1521 (Online), ISSN 2226-2830 (Print) ВІСНИК МАРІУПОЛЬСЬКОГО ДЕРЖАВНОГО УНІВЕРСИТЕТУ СЕРІЯ: ІСТОРІЯ. ПОЛІТОЛОГІЯ, 2019, ВИП. 25

новация, которая заключается в противопоставлении государств-кредиторов и должников. Эта технология американского империализма закреплена в соответствующих положениях международного права, осуществляется за счет функционирования компетентных организаций и учреждений. К. Шмитт отмечает «гибкость и изобретательность американского империализма, что подтверждается тактикой заключения протекционных договоров и разработкой похожих на эти договоры вариантов правовых обоснований, позволяющих прямое вмешательство во внутренние дела других государств» [4, с. 351]. В качестве примера мыслитель называет систему интервенционных договоров США с такими странами как Куба, Гаити, Панама и др. Данные государства формально остаются суверенными, но попадают в многостороннюю зависимость от Америки. В частности, Куба, которая получила свободу в 1898 г. «из рук США» в результате войны между Америкой и Испанией. Событие стало, с одной стороны, резонансным в глазах мировой общественности «мужественный великий народ вступил в войну, чтобы обеспечить независимость другого народа» [4, с. 356]. С другой стороны, Куба была вынуждена сразу же заключить договор с США, согласно которому Америка, не только защищала кубинцев, но и получила право определять уровень компетентности кубинского правительства в решении вопросов собственности, свобод для населения и др. Кроме того, К. Шмитт обращает внимание на важную особенность, а именно: размещенные на острове финансовые капиталы передавались под контроль Америки; в договоре закреплялась также передача американцам военно-морских баз, угольных и нефтяных месторождений. Следует добавить, что в течение первого десятилетия ХХ в. США для обеспечения своих интересов неоднократно осуществляли высадку войск на территории Кубы.

К. Шмитт отмечает своеобразность договора с юридической точки зрения, что, «прежде всего, данный договор заключен США с суверенной республикой, при этом Америка в 1901 г. оказала серьезное давление на Национальное собрание республики за счет военного присутствия и добилась включения положений договора в Конституцию страны; политический аспект договора заключается в потенциальной угрозе мировому сообществу со стороны США за счет военных баз на территории Кубы при полной парализации внешних сношений республики» [4, с. 357].

В своем анализе системы интервенционных договоров ученый уделяет большое внимание тактике США во взаимоотношениях с Панамой. Стратегический объект Панамский канал находится в политическом владении и под военной защитой США. В мирное время канал может использоваться всеми государствами, но по договору с Америкой Панама обязуется защищать интересы США относительно канала в любой конфликтной ситуации и, кроме того выступать на стороне американцев, где бы ни велись боевые действия. Ситуация с Панамой примечательна тем, что наряду с существующим договором, в значительной мере негативно влияющим на суверенитет республики, Панама является государством-членом Лиги наций, а с февраля 1932 г. - членом Совета Лиги наций. Таким образом, метод интервенционных договоров приобретает наиболее интенсивную форму подчинения одним государством другого государства. При этом К. Шмитт замечает, что «тактика интервенционных договоров США не распространяется, «во всяком случае, пока», на другие континенты, кроме американского» [4, с. 359].

В арсенале США есть еще одно эффективное средство осуществления гегемонии над латиноамериканскими государствами, а именно «признание новых правительств». В латиноамериканских государствах, отмечает К. Шмитт, нередко происходят революции и перевороты. Деятельность вновь сформированных правительств в высокой мере зависит от 
ISSN 2518-1521 (Online), ISSN 2226-2830 (Print)

ВІСНИК МАРІУПОЛЬСЬКОГО ДЕРЖАВНОГО УНІВЕРСИТЕТУ

СЕРІЯ: ІСТОРІЯ. ПОЛІТОЛОГІЯ, 2019, ВИП. 25

степени лояльности со стороны Соединенных Штатов, которые не признают революционные правительства и ориентируются только на легальные правительства. Вопросы легальности или нет тех или иных правительств решают США и, следует признать, придают общим международным принципам большое значение. За пределами американского пространства США применяют другие методы распространения своего влияния, в частности, К. Шмитт отмечает особенности американской политики после Первой мировой войны: создание при инициативе и под давлением Америки Лиги наций, в которую, в итоге, Америка не вступила. Но за счет признания и закрепления доктрины Монро [1] в ст. 21 Устава Лиги наций, США получили мощный рычаг воздействия на политические процессы в Европе.

Если задать вопрос, продолжает К. Шмитт, что из себя представляет доктрина Монро с многочисленными неясностями, противоречиями, необоснованными требованиями и правопритязаниями, то, прежде всего следует выделить главное - это односторонняя правительственная декларация США. Доктрину нельзя считать договором, поскольку содержание не согласовывалось с другими государствами. При этом положения доктрины умело интерпретируются в зависимости от ситуации для сохранения и укрепления американских интересов. К. Шмитт подчеркивает также важность вопроса, в какой мере можно рассматривать доктрину как политическую максиму и насколько она связана с международным правом. В этой связи мыслитель приводит слова госсекретаря США Р. Олни, который говорил в 1895 г., что «доктрина Монро является частью американского публичного права, основывается на общих принципах права (например, право на самооборону), поэтому доктрина - это право, а не только политика» [4, с. 354]. В свою очередь госсекретарь США Ч. Нокс выразил в 1911 г. противоположную позицию, утверждая, что «доктрина с правом в техническом смысле ничего общего не имеет и базируется на политике и власти» [4, с. 354]. Собственная позиция К. Шмитта заключается в том, что «доктрина, без сомнения, политический инструмент, поскольку любой элемент международного права - это политическое явление, но формально доктрину можно причислить к понятиям международного права, тем более она закреплена в Уставе Лиги наций» $[4$, с. 355$]$.

К. Шмитт отмечает огромный успех Америки в том, что ей удалось доктрину материализовать таким образом, что другие государства вынуждены признать требования американцев без права обсуждения и предъявления каких-либо критических аргументов. Своеобразность ситуации раскрывает следующий факт: 18 американских государств, треть членов Лиги наций, которые находятся в зависимости от США, принимают под контролем США участие в решении европейских и азиатских проблем. При этом любое вмешательство в сферу интересов США недопустимо. Функционирует, замечает К. Шмитт, «интересная система: американская политика, когда речь заходит о Европе, официально отсутствует, но в реальности эффективно присутствует» [4, с. 361]. Политика со стороны Лиги наций по отношению к США может оказывать влияние на США, но лишь в пределах, которые они одобряют.

К. Шмитт признает заслугу Америки в том, что она впервые предложила обстоятельную инициативу относительно разоружения. Имеется в виду «Пакт Келлога» [2], подписанный в 1928 г. в Париже рядом государств и позже большинством стран мира. Торжественное объявление отказа от войны поступило из Вашингтона, подчеркивает К. Шмитт, а не из Женевы и было с воодушевлением воспринято мировой общественностью. Но при этом мыслитель обращает внимание на то, что «возникает 
ISSN 2518-1521 (Online), ISSN 2226-2830 (Print) ВІСНИК МАРІУПОЛЬСЬКОГО ДЕРЖАВНОГО УНІВЕРСИТЕТУ СЕРІЯ: ІСТОРІЯ. ПОЛІТОЛОГІЯ, 2019, ВИП. 25

целый ряд вопросов: кто обеспечивает мир на земле, кто решает, что такое мир, порядок и безопасность, кому принадлежат полномочия определять приемлемость или нет конкретного состояния» [4, с. 362]. Получается, продолжает К. Шмитт, что правительству США предоставлено право, принимать решения относительно мира на земле, именно «Пактом Келлога», что является единственной документально закрепленной и поддержанной почти всеми государствами альтернативой войне. При этом особенность заключается в том, что в документе войне как таковой приговор не выносится, и она полностью не запрещается. В Пакте не зафиксирована идея «никогда больше не быть войне», а провозглашается отказ от войны, лишь как инструмента национальной политики, но нет ответа на вопрос, когда война считается инструментом национальной политики и ничего не сказано о других видах войны, выходит, что юридически они разрешены. Правда, отмечает К. Шмитт, попытка дать определение войны как инструмента национальной политики была предпринята А. Брианом, одним из инициаторов Пакта в переписке с Ф. Келлогом. «Война, которая ведется с целью произвола, корысти и демонстрирует несправедливость, считается инструментом национальной политики», но при этом попутно, в результате общения двух государственных деятелей, четко обозначилась позиция, согласно которой «войны, ведущиеся в рамках международной политики, имеют оправдание» [4, с. 363].

Империализм не ведет национальные войны, а войны в интересах международной политики с активным применением войск и техники вообще войнами не считаются, хотя при тех же условиях действия со стороны кого-то другого квалифицировались бы как собственно война, пишет К. Шмитт. После Первой мировой войны в разных точках земли постоянно присутствуют разномасштабные вооруженные противостояния, которые войнами не считаются и не бойкотируются, что же тогда называется войной, спрашивает К. Шмитт, называя в качестве примера кровопролитные столкновения между Китаем и Японией. По мнению К. Шмитта, представляет интерес трактовка ситуации известного женевского ученого-правоведа Г. Веберга, который пишет, что по законам действующего права в случае с китайско-японским конфликтом допустимо говорить о военной оккупации, а не о войне, данные события не исключают формулировки «мирной оккупации» с применением вооруженных сил для защиты жизни и собственности японских граждан и как репрессалии на нарушения положений международного права китайской стороной. «Как возможно в рамках юриспруденции рассуждать о «мирной оккупации», а не о войне на фоне кровопролитных сражений, десятков тысяч убитых и вообще подвергать насмешке понятие мир», с возмущением отмечает К. Шмитт и добавляет: «ход мыслей по данной ситуации должен быть следующим: или мир или война; что есть война - то, что является немирным средством, что такое мирное средство - то, что не связано с военными действиями, третьего не дано» [4, с. 363]. Пакт Келлога в решении данной проблемы не поможет, к документу обращаться нечего, приходит к заключению К. Шмитт. При этом он подвергает резкой критике Лигу наций, которая видит свои функции лишь в юридическом оформлении международных отношений, в этом плане дело находится в полном порядке, но инертность по отношению к существующим вооруженным противостояниям является глубоко ошибочной позицией.

Женевская Лига наций является не только политической структурой, но и оснащенным конкретным арсеналом методов особым типом империализма, пишет К. Шмитт в своей работе «Frieden oder Pazifismus?» («Мир или пацифизм?». 1933 г.) [5], которая представляется отечественному исследователю впервые. По отношению к 
ISSN 2518-1521 (Online), ISSN 2226-2830 (Print)

ВІСНИК МАРІУПОЛЬСЬКОГО ДЕРЖАВНОГО УНІВЕРСИТЕТУ

СЕРІЯ: ІСТОРІЯ. ПОЛІТОЛОГІЯ, 2019, ВИП. 25

незначительным событиям и процессам Лига реагирует оперативно и авторитетно. «Но когда наблюдаются очевидные нарушения принципов права такие как интервенции и настоящие войны, Лига не предпринимает никаких шагов и остается в стороне. Лиге наций не удалось стать организацией, которая обеспечила бы мир в Европе и на всей земле» [5, c. 378]. Вместо этого создан комплекс формальных правовых понятий, большинство из которых фикции, прямо искажающие суть политической жизни. Специфика методов женевского пацифизма заключается в том, что объективное право народов подменяется юридическими формулировками и дефинициями. К. Шмитт говорит о бесконечных заседаниях Лиги с целью установить, что считать разоружением, вооружением, агрессией, обороной и. т. д. Что касается агрессии, то, действительно, бывает непросто разобраться, кто явный, или кто предполагаемый агрессор. Но сомнений не возникает, когда с одной стороны выступает государство, оснащенное всеми современными военными средствами и с другой стороны полностью безоружный народ. К. Шмитт имеет в виду демилитаризованные зоны на территории Германии после Первой мировой войны, в которых «каждая попытка мобилизации расценивается как проявление агрессии и угрозы миру со стороны Германии; пацифизм Женевы направлен таким образом не против вооруженных, а против беззащитных фигурантов» [5, с. 379].

Мы должны подумать о судьбе Германии, обратить серьезное внимание на комплекс теоретических и практических методов империализма, приходит в 1932 г. к выводу К. Шмитт. Наивысшая степень угрозы со стороны империализма заключается скорее не в военном потенциале и не в финансово-экономическом могуществе, а в способности интерпретировать содержание политических и правовых понятий по своему усмотрению. «Данная тактика империализма крайне опасна, может быть даже опаснее чем военная интервенция и экономическая эксплуатация, все это касается Германии, которая занимает пока «оборонительные позиции». Народ считается побежденным, если он покоряется чужому вокабулярию и представлениям о том, что называется правом и особенно международным правом, поэтому мы должны сохранять бдительность, не допустить уничтожения нашего суверенитета» [4, с. 365].

Чтобы проследить, как совершенствовалась тактика империализма после Второй мировой войны, следует, на наш взгляд, обратить внимание на рассуждения К. Шмитта в 1952 г. в работе «Die Einheit der Welt» («Единство мира») [6]. Он пишет, что речь идет о чрезвычайно сложном понятии, о единстве властных структур, которые организовывают и управляют всем человечеством. «Желание создать дееспособное глобальное единство мира связано с господствующим в настоящий момент индустриально-техническим мировоззрением. Техническое развитие неизбежно ведет к возникновению новых централизованных органов управления и влияния, и если бы на самом деле техника, а не политика решала судьбу человечества, то проблему единства можно было бы считать закрытой» [6, с. 496].

Политическая действительность - дуализм могучих противников Запада и Востока, «противостояние экономических систем, идеологий, классов и групп; противоборство проявляется в элементах «холодной» и открытой войны, в дипломатических, пропагандистских и моральных манипуляциях» [6, с. 498]. Существующий дуализм чрезвычайно опасен, продолжает К. Шмитт, возможно ситуация будет продолжаться дольше, чем предполагает большинство людей, но в любом случае необходимо конкретное решение. Ученый не исключает вариант вооруженной борьбы (войны), где каждый из противников оправдывает свои действия разными целями, например, «в интересах 
ISSN 2518-1521 (Online), ISSN 2226-2830 (Print) ВІСНИК МАРІУПОЛЬСЬКОГО ДЕРЖАВНОГО УНІВЕРСИТЕТУ СЕРІЯ: ІСТОРІЯ. ПОЛІТОЛОГІЯ, 2019, ВИП. 25

человечества». Но «если война ведется во имя человечества, то здесь имеет место особенно интенсивный политический смысл, закрепление интересов определенного государства, поскольку понятие «человечество» является особенно выгодным идеологическим инструментом империалистических экспансий и аргументацией действий экономического империализма» [7, с. 55]. Победитель стал бы единственным властелином мира и создавал бы единство мира по своему усмотрению в духе своих идей.

К. Шмитт отмечает, что победа одного из противников не является единственной возможностью устранения напряженности существующего дуализма, в данном противостоянии не может раствориться масштабность понятия «всего человечества». Речь идет о значении, например, Индии, Китая или арабского мира, которые создают предпосылки для функционирования плюрализма «больших пространств», о которых писал в свое время американский мыслитель У. Джеймс. У. Джеймс был убежден, что «мысль о единстве мира несвоевременна, поскольку существует множество мировых систем» $[6$, с. 498]. К. Шмитт развивает идеи американского ученого и говорит о «третьей силе», которая также стремится к конкретным властным пределам с сознательной ориентировкой на могучих партнеров. К. Шмитт подчеркивает, что каждый из противников прикладывает усилия для того, чтобы всеми средствами, включая международное право, привлечь на свою сторону как можно больше представителей «третьей силы» с целью усиления натиска на оппонента. При этом мыслитель обращает внимание на ошибочность мнения о приоритетности нейтральной политики для «третьей силы». „Эта сила создает не простую триаду, а множественность, обеспечивающую реальный плюрализм, что способствует сохранению равновесия между «большими пространствами» и формированию нового международного права» [6, с. 500].

На наш взгляд, современную Украину можно отнести к группе государств «третьей силы», в «духе Шмитта». Украине во взаимоотношениях с западными партнерами важно учитывать политические риски, связанные с неизбежной сутью империализма, о чем профетически писал К. Шмитт.

\section{Список использованной литературы}

1. Доктрина Монро [Электронный ресурс] // Международное право. - Режим доступа : interlaws.ru/doktrina-monro/; Doktrina Monro [Elektronnyy resurs] // Mezhdunarodnoe pravo. - Rezhim dostupa : interlaws.ru/doktrina-monro/

2. Келлога-Бриана пакт 1928 года, 27 августа [Электронный ресурс] // Документы XX века. - Режми доступа : http://www.doc20vek.ru/node/3452 ; Kelloga-Briana pakt 1928 goda, 27 avgusta [Elektronnyy resurs] // Dokumenty XX veka. - Rezhmi dostupa : http://www.doc20vek.ru/node/3452

3. Устав Лиги Наций. 1919 [Электронный ресурс]. - Режим доступа : http://www.hist.msu.ru/Departments/ModernEuUS/INTREL/SOURCES/Legnatust.htm ; Ustav Ligi Natsiy. 1919 [Elektronnyy resurs]. - Rezhim dostupa : http://www.hist.msu.ru/Departments/ModernEuUS/INTREL/SOURCES/Legnatust.htm

4. Schmitt C. USA und die völkerrechtlichen Formen des modernen Imperialismus (1932) / C. Schmitt // Frieden oder Pazifismus? Arbeiten zum Völkerrecht und zur internationalen Politik 1924-1978. Hrsg., von G. Maschke Duncker \& Humblot, Berlin, 2005. - 1010 s.

5. Schmitt C. Frieden oder Pazifismus (1933) / C. Schmitt // Frieden oder Pazifismus? Arbeiten zum Völkerrecht und zur internationalen Politik 1924-1978. / Hrsg., von G. Maschke Berlin : Duncker \& Humblot., 2005. - 1010 s. 
ISSN 2518-1521 (Online), ISSN 2226-2830 (Print)

ВІСНИК МАРІУПОЛЬСЬКОГО ДЕРЖАВНОГО УНІВЕРСИТЕТУ

СЕРІЯ: ІСТОРІЯ. ПОЛІТОЛОГІЯ, 2019, ВИП. 25

6. Schmitt C. Die Einheit der Welt / C. Schmitt // Staat, Großraum, Nomos. Hrsg., von G. Maschke. - Berlin: Duncker \& Humblot, 1995. - 688 s.

7. Schmitt C. Der Begriff des Politischen / C. Schmitt. - Berlin : Duncker \& Humblot, 1963. - $78 \mathrm{~s}$.

Стаття надійшла до редакції 07.06.2019 p.

\section{Shumsky}

CARL SCMITT ON THE ISSUE OF POLITICAL TECHNOLOGIES OF AMERICAN AND EUROPEAN IMPERIALISM IN INTERNATIONAL LAW

The present paper concerns the positions of the German political thinker and prominent legal scholar Carl Schmitt regarding the strategic and tactical actions of American and European imperialism aimed at expanding the spheres of political and economic domination in the world arena under international law. American imperialism, as C. Schmitt notes, is considered to be the most modern imperialism according to generally accepted ideas, because it is primarily economic imperialism, and not military one. The "economic" is brought to the fore in order to veil the fact of imperialism altogether by opposing economics and politics in the 19th century, when "economic" was qualified as "non-political" and, accordingly, "political" was viewed as "non-economic". c. Schmitt believes that generally accepted in the XIX century position of the "economic" priority in the confrontation with the "political" has lost its relevance. The process of expanding the power of imperialism is accompanied by a search for certain "substantiations" and the development of principles for legitimizing actions that become non-peaceful. Imperialism needs convincing international legal concepts and provisions that predominantly represent ideological performances and pursue propaganda goals. C. Schmitt reveals the imperialistic essence of the Monroe doctrine, harshly criticizes the action of the League of Nations, which in his opinion is not only a political structure, but also special type of imperialism equipped with a specific arsenal of methods. In modern conditions, in relations with Western partners, it is important for Ukraine to take into account the political risks associated with the inevitable essence of imperialism, which C. Schmitt wrote prophetically. Ukraine is in the stage of political modernization, and this leads to objective difficulties in finding adequate algorithms for political processes that ensure the preservation of independence in the era of global between the imperialist ambitions of the West and the East.

Keywords: imperialism, international law, League of Nations, law, war, peace, state, treaty.

\section{Л.М. Шумський}

\section{КАРЛ ШМИТТ ПРО ПОЛІТИЧНІ ТЕХНОЛОГІЇ АМЕРИКАНСЬКОГО ТА СВРОПЕЙСЬКОГО ІМПЕРІАЛІЗМУ В МІЖНАРОДНОМУ ПРАВІ}

У статті проаналізовані позицї німецького політичного мислителя $i$ видатного вченого-правознавия Карла Шмітта щуодо стратегічних і тактичних дій американського i європейського імперіалізму, спрямованих на розширення сфер політичного і економічного панування на світовій арені в рамках міжнародного права. Американський імперіалізм, як зазначає К. Шмітт, вважається за загальноприйнятими уявленнями найсучаснішим імперіалізмом, тому щзо він, перш за все, є економічним імперіалізмом, а не військовим. «Економічне» виноситься на передній план, щуоб взагалі завуалювати факт імперіалізму за допомогою протиставлення економіки i політики в XIX столітті, коли «економічне» кваліфікувалося як «не політичне» $i$ відповідно «політичне» розглядалося як «не 
ISSN 2518-1521 (Online), ISSN 2226-2830 (Print)

ВІСНИК МАРІУПОЛЬСЬКОГО ДЕРЖАВНОГО УНІВЕРСИТЕТУ

СЕРІЯ: ІСТОРІЯ. ПОЛІТОЛОГІЯ, 2019, ВИП. 25

економічне». К. Шмітт вважає, щзо загальноприйнята в ХІХ в. позиція пріоритету «економічного» в протистоянні 3 «політичним» втратила актуальність. Процес розширення владної могутності імперіалізму супроводжується пошуком певних «обтрунтувань» і розробкою приничиів легітимації дій, які набувають немирний характер. Імперіалізму необхідні переконливі міжнародно-правові поняття $i$ положення, які $\epsilon$ переважно ідеологічними інсиенуваннями і переслідують, крім того пропагандистські цуілі. К. Шмітт розкриває імперіалістичну суть доктрини Монро, піддає різкій критиці дї̈ Ліги начій, яка на його думку є не тільки політичною структурою, а й оснащеним конкретним арсеналом методів особливим типом імперіалізму. Українї в сучасних умовах у взаєминах із західними партнерами важливо враховувати політичні ризики, пов'язані з неминучою суттю імперіалізму, про щзо профетично писав К. Шмітт. Україна знаходиться в стадї політичної модернізащії, і изим обумовлюються об'єктивні складнощі в пошуку адекватних алгоритмів політичних прочесів, щзо забезпечують збереження незалежності в епоху глобальних протистоянь між імперіалістичними амбіціями Заходу і Сходу.

Ключові слова: імперіалізм, міжнародне право, Ліга націй, закон, війна, мир, держава, договір. 